University of St. Thomas, Minnesota

UST Research Online

$10-2012$

\title{
Understanding the Impact of Collaboration Software on Product Design and Development
}

\author{
Ozer Asdemir \\ University of St. Thomas, Minnesota, oasdemir@stthomas.edu \\ Rajiv D. Banker \\ Temple University, banker@temple.edu \\ Indranil Bardhan \\ University of Texas at Dallas, bardhan@utdallas.edu
}

Follow this and additional works at: https://ir.stthomas.edu/ocbacctpub

Part of the Accounting Commons

This Paper is brought to you for free and open access by the Accounting at UST Research Online. It has been accepted for inclusion in Accounting Faculty Publications by an authorized administrator of UST Research Online. For more information, please contact asle4660@stthomas.edu. 


\title{
informs , institutefor op porations Research
}

\author{
Understanding the Impact of Collaboration Software on Product Design and Development \\ Author(s): Rajiv D. Banker, Indranil Bardhan and Ozer Asdemir \\ Reviewed work(s): \\ Source: Information Systems Research, Vol. 17, No. 4 (December 2006), pp. 352-373 \\ Published by: INFORMS \\ Stable URL: http://www.jstor.org/stable/23015811 \\ Accessed: 29/09/2012 01:09
}

Your use of the JSTOR archive indicates your acceptance of the Terms \& Conditions of Use, available at http://www.jstor.org/page/info/about/policies/terms.jsp

JSTOR is a not-for-profit service that helps scholars, researchers, and students discover, use, and build upon a wide range of content in a trusted digital archive. We use information technology and tools to increase productivity and facilitate new forms of scholarship. For more information about JSTOR, please contact support@jstor.org. 


\title{
Understanding the Impact of Collaboration Software on Product Design and Development
}

\author{
Rajiv D. Banker \\ Fox School of Business, Temple University, 1810 North 13th Street, Philadelphia, Pennsylvania 19122, banker@temple.edu \\ Indranil Bardhan \\ School of Management, University of Texas at Dallas, 2601 North Floyd Road, Richardson, Texas 75083-0688, \\ bardhan@utdallas.edu \\ Ozer Asdemir \\ College of Business, University of St. Thomas, Mail MCH 316, 2115 Summit Avenue, St. Paul, Minnesota 55105-1096,
} oasdemir@stthomas.edu

\begin{abstract}
Drior research suggests that supply chain collaboration has enabled companies to compete more efficiently 1 in a global economy. We investigate a class of collaboration software for product design and development called collaborative product commerce (CPC). Drawing on prior research in media richness theory and organizational science, we develop a theoretical framework to study the impact of CPC on product development. Based on data collected from 71 firms, we test our research hypotheses on the impact of CPC on product design quality, design cycle time, and development cost. We find that CPC implementation is associated with greater collaboration among product design teams. This collaboration has a significant, positive impact on product quality and reduces cycle time and product development cost. Further analyses reveal that CPC implementation is associated with substantial cost savings that can be attributed to improvements in product design quality, design turnaround time, greater design reuse, and lower product design documentation and rework costs.
\end{abstract}

Key words: collaborative product commerce; new product development; collaboration software

History: V. Sambamurthy, Senior Editor; Rajiv Sabherwal, Associate Editor. This paper was received on

January 4, 2005, and was with the authors 9 months for 3 revisions.

\section{Introduction}

The accelerating rate of technological change, coupled with growing demand for customized products has dramatically reduced product life cycles. There is increasing reliance on the use of information technology (IT) to manage the product development life cycle (Krishnan and Ulrich 2001, Nambisan 2003). Collaborative product commerce (CPC) is a relatively new, Web-based technology used to streamline product design and development processes that are not well structured or that require significant manual intervention. CPC software enables product design engineers to collaborate by facilitating the sharing of product data used in the design, development, and management of products (Welty and Becerra-Fernandez 2001, Carroll 2001). ${ }^{1}$ Specific business processes that can be

\footnotetext{
${ }^{1}$ These systems have also been labeled product life cycle management (PLM) systems because they go beyond the realm of basic product data management and span other processes within the
}

facilitated include product data management, product design, product development-cycle management, product introduction, change request management, engineering change implementation, and strategic sourcing.

Little attention has been given to studying the impact of information systems on product development. In a recent article, Krishnan and Ulrich (2001, p. 15) concluded that "the benefit of new tools to manage product knowledge and support development decision making within the extended enterprise needs to be explored in greater detail." In this research, we develop a conceptual framework to study the impact of CPC on the extent of collaboration between product design teams involved in the development of new products. We draw on prior research in new product development, organizational science, and software

product development life cycle to enable interorganizational, crossfunctional collaboration (O'Marah 2001). 
engineering to better understand the role of collaboration in product development and test our hypotheses regarding the impact of CPC on product design and development. Using product design and development data collected from a cross-sectional survey of 71 companies, we empirically test our hypotheses regarding the impact of the implementation of $\mathrm{CPC}$ software on product development.

We find that CPC has a significant impact on the level of collaboration among product design teams. Furthermore, improvements in the frequency and intensity of collaboration leads to improved performance, in terms of greater product design quality, lower design cycle time, and reduced product development cost. We find that it is important to consider both direct and indirect effects of CPC because the impact of CPC on product quality, cycle time, and cost is partially mediated through improvements in team collaboration. Our primary contribution to the extant literature on collaboration is to (a) develop a better understanding of the role of IT in product development, and (b) empirically validate the impact of collaboration software on product development with data from a cross-section of firms.

\section{Conceptual Foundations}

In this section, we describe the role of CPC in product development, and draw on prior research in product development and media richness theory to develop our research model.

\subsection{Literature Review}

Effective communication among product development teams is an important element of research and development (R\&D) performance (De Meyer 1991). One of the most important issues in improving $\mathrm{R} \& \mathrm{D}$ productivity is stimulating communication among virtual product design teams (Nambisan 2002, Loch and Terwiesch 1998). Because product design engineers often deal with unstable and volatile product design information and must communicate critical parameters as they become known, collaboration among design teams is critical to mitigate the impact of information uncertainty and reduce ambiguity related to imprecise product design data (Sosa et al. 2002, Clark and Fujimoto 1991, Hoegl and Gemuenden 2001). While collaboration within a product design team involves information exchange between team members, collaboration across teams entails a greater number of interfaces and handoffs necessary to synchronize information and product design data across team boundaries.

Most prior research in product development has focused primarily on the people and process dimensions, while the role of IT has generally been ignored. Tushman (1977) showed that high levels of interactions and coordination between interdependent groups are necessary to successfully complete complex tasks. The impact of interteam communication on project success has also been studied by Ancona and Caldwell $(1990,1992)$ and summarized by Brown and Eisenhardt (1995) in their review on product development. Recently, Hoegl et al. (2004) studied longitudinal project data on 39 projects and showed that interteam coordination has a positive impact on project performance. They did not investigate the role of IT in facilitating interteam collaboration and their results were based on a small sample of projects within a single firm. Easley et al. (2003) explored a group communication system in a university environment and found that collaborative system use has a positive impact on teamwork quality and performance. Terwiesch et al. (2002) suggested that the role of the IT medium used for information exchange in product development needs to be further examined.

The nature of collaboration during product development ranges from face-to-face meetings and electronic communications involving phone, fax, and e-mail, to the exchange of formal design documents through shared databases and groupware. The frequency and intensity of such interactions depend on several factors, including missing product data, ease of access, data definition, and identification and evaluation of alternative designs (Davis et al. 2001). ${ }^{2}$ In many firms, these interactions are not structured, and the ability to collaborate effectively is impeded by the lack of a single platform and appropriate standards to exchange product data.

\footnotetext{
${ }^{2}$ Interactions between product design engineers are typically structured around engineering drawings, product specifications, design inputs and outputs, test reports, and engineering change orders (Liker et al. 1992). See Davis et al. (2001) for a schematic representation of information flow between entities involved in product development.
} 


\begin{tabular}{|c|c|c|c|c|c|c|}
\hline & $\begin{array}{c}\text { Phase } 0 \\
\text { Product concept } \\
\text { and initiation }\end{array}$ & $\begin{array}{c}\text { Phase } 1 \\
\text { Product development } \\
\text { proposal }\end{array}$ & $\begin{array}{c}\text { Phase } 2 \\
\text { Research and } \\
\text { development }\end{array}$ & $\begin{array}{c}\text { Phase } 3 \\
\text { Product } \\
\text { development and } \\
\text { manufacturing } \\
\text { design }\end{array}$ & $\begin{array}{c}\text { Phase } 4 \\
\text { Product design } \\
\text { verification and } \\
\text { manufacturing } \\
\text { development }\end{array}$ & $\begin{array}{l}\text { Phase } 5 \\
\text { Pilot production and } \\
\text { product introduction }\end{array}$ \\
\hline \multirow[t]{7}{*}{ Tasks/activities } & Concept document & Project plan & Concept review & $\begin{array}{l}\text { Prototype verification } \\
\text { tests }\end{array}$ & Design outputs & $\begin{array}{l}\text { Marketing plan } \\
\text { implementation }\end{array}$ \\
\hline & \multirow[t]{6}{*}{ Product requirements } & Design inputs & $\begin{array}{l}\text { Preliminary bill of } \\
\text { materials }\end{array}$ & $\begin{array}{l}\text { Customer approval } \\
\text { of prototype }\end{array}$ & $\begin{array}{l}\text { Design verification } \\
\text { testing }\end{array}$ & $\begin{array}{l}\text { Quality-control } \\
\text { system evaluation }\end{array}$ \\
\hline & & Product strategy & $\begin{array}{l}\text { Preliminary supplier } \\
\text { selection }\end{array}$ & Certified design & $\begin{array}{l}\text { Production material } \\
\text { on order }\end{array}$ & $\begin{array}{l}\text { Preliminary process } \\
\text { capability study }\end{array}$ \\
\hline & & $\begin{array}{l}\text { Preliminary product } \\
\text { specifications }\end{array}$ & $\begin{array}{l}\text { Preliminary } \\
\text { manufacturing } \\
\text { process plan }\end{array}$ & Final bill of materials & Operator instruction & End-of-line audit \\
\hline & & \multirow[t]{3}{*}{$\begin{array}{l}\text { Preliminary test } \\
\text { plan }\end{array}$} & $\begin{array}{l}\text { Final engineering } \\
\text { test plan }\end{array}$ & Manufacturing plans & $\begin{array}{l}\text { Pilot run production } \\
\text { process }\end{array}$ & $\begin{array}{l}\text { Preventive } \\
\text { maintenance plan }\end{array}$ \\
\hline & & & $\begin{array}{l}\text { Prototype control } \\
\text { plan }\end{array}$ & $\begin{array}{l}\text { Manufacturing } \\
\text { process plans }\end{array}$ & \multirow[t]{2}{*}{$\begin{array}{l}\text { Production } \\
\text { verification and } \\
\text { validation testing }\end{array}$} & \multirow[t]{2}{*}{$\begin{array}{l}\text { Customer approval } \\
\text { of pilot samples }\end{array}$} \\
\hline & & & $\begin{array}{l}\text { Final product } \\
\text { specification }\end{array}$ & Capital approval & & \\
\hline
\end{tabular}

We extend the current body of knowledge on collaboration by studying the role of a specific class of IT (i.e., CPC) in facilitating collaboration within a product development environment. CPC comprises a class of software that facilitates management and communication of product data generated during product design and development. CPC provides a multitude of capabilities, including communication, visualization, calculation, and simulation tools that enable creation of new product knowledge (Yassine et al. 2004). CPC enables product design teams to collaborate across interorganizational boundaries to gather and share design requirements, conduct design iterations, verify and test product designs, and provide the final design handoffs to other departments (Adler 1995, McGrath and Iansiti 1998). CPC supports a broad range of system-to-system collaboration capabilities for processing of structured and unstructured product design data (Nambisan 2003, Baba and Nobeoka 1998). The scope of CPC software includes several processes that comprise the product development life cycle as described in Table $1 .^{3}$

While several articles have touted the perceived benefits of CPC and their impact on product devel-

\footnotetext{
${ }^{3}$ Heterogeneity among technologies used for product development is not an issue because we controlled for it in our questionnaire by defining the scope and functionality of the CPC software.
}

opment processes (Carroll 2001, Port 2003, Mulani and Matchette 2001), these claims are based on anecdotal evidence and are not supported by empirical research. ${ }^{4}$ We propose a theoretical framework to better understand how CPC software facilitates collaboration and we use real-world data to empirically study its impact on the outcomes of product development.

\subsection{Theoretical Framework}

The need for intra- and interteam collaboration during product development arises due to task interdependencies and the volatility of information content during the design creation and development process (Hoegl et al. 2004, Terwiesch et al. 2002). Task interdependencies refer to the intensity and flow of information exchange between design teams and are dependent on the complexity of the product architecture (Gerwin and Moffat 1997). Product design projects typically consist of several interdependent modules where the work of one team is dependent on work in other teams. Because different work streams

\footnotetext{
${ }^{4}$ General Motors and Boeing represent well-cited success stories of design collaboration. GM's system connects 11 of its 14 global design groups such that design work on a car built for the Brazilian market is split between Germany and Brazil. Such collaboration shortened the design cycle time from 36 to 18 months (Mulani and Lee 2001).
} 
need to be synchronized to meet project schedules and budget constraints, effective collaboration is critical to mitigate the risks emanating from poor coordination, which may lead to significant rework and project delays (Joglekar et al. 2001, Loch and Terwiesch 1998, Hoegl et al. 2004).

We draw on prior research on media-richness theory and virtual teams to develop a better understanding of the impact of collaboration software on product design and development. Media richness represents the capacity of communication media to process information that can overcome diverse frames of reference, support communication across multiple channels, and allow managers to coordinate interand intraorganizational communications (Dennis and Kinney 1998). Daft and Lengel (1986) argued that the richness of information processed by communication media facilitates the quality of inter- and intrafirm collaboration. DeSanctis and Jackson (1994) and Maznevski and Chudoba (2000) showed that the benefits of using more-complex communications technologies increased as the tasks became more complex. Recent research suggests that rich media may be particularly important where time to market is a critical factor and multiple parties must conduct complex activities in an integrated manner. Based on a study of third-party logistics companies, Vickery et al. (2004) showed that media-rich communications have a positive effect on customer relational performance by enabling communication capabilities that strengthen customer-supplier relationships.

Information-rich media permit transmission of complex or tacit knowledge, or both, and support extensive versus routine problem solutions (Yassine et al. 2004, Vickery et al. 2004). Daft and Lengel (1986) argued that managers rely on rich information when there is high uncertainty and when problems involve interfaces across organizational boundaries (Moenaert and Souder 1996). Hence, media richness is particularly relevant to product design and development, which is characterized by high complexity and turbulence arising from project interdependencies that result in product design changes and new interfaces (Hoegl et al. 2004, Hinds and Kiesler 1995, Thomke and Reinertsen 1998). Electronic media, such as CPC, can be classified on the high end of the media richness spectrum, which relates information richness to the complexity of organizational phenomena (Vickery et al. 2004, p. 1109).

CPC software provides an information-rich medium that supports product design collaboration by facilitating synchronous communication within and across product development teams. CPC facilitates efficient data storage, electronic retrieval and reuse of product designs, and allows engineers to compress the overall product development time by reducing latency. Improvements in design quality arise from the ability to electronically share design ideas between team members, and conduct real-time version control, which enables engineers to track design defects and implement design changes more efficiently. Hence, the basic premise of CPC implementation is that improvement in product design cycle time, cost, and quality can be attained by greater collaboration among product design teams. Figure 1 describes our research framework in terms of the relationships between CPC and product development outcomes.

\section{Research Hypotheses}

We draw on prior research primarily from two streams of literature-product development and media-richness theory - to guide the development of our research hypotheses.

\subsection{Collaboration}

Product development processes entail knowledge creation and information sharing across organizational boundaries. Collaboration among product design teams typically entails sharing of knowledge that exists in two forms: explicit and tacit (Nonaka 1994, Yassine et al. 2004). While explicit knowledge involves design data that can be easily codified, stored, and transferred, tacit knowledge is created through a design engineer's experience such as the critical judgment involved in making product design decisions (Nambisan 2002).

In order to understand how CPC supports collaboration, it is necessary to develop an understanding of four types of processes involved in effective knowledge creation: socialization, externalization, internalization, and combination (Nonaka 1994). Socialization involves the use of social processes that enables design engineers to acquire and transfer tacit knowledge 
Figure 1 Conceptual Research Model

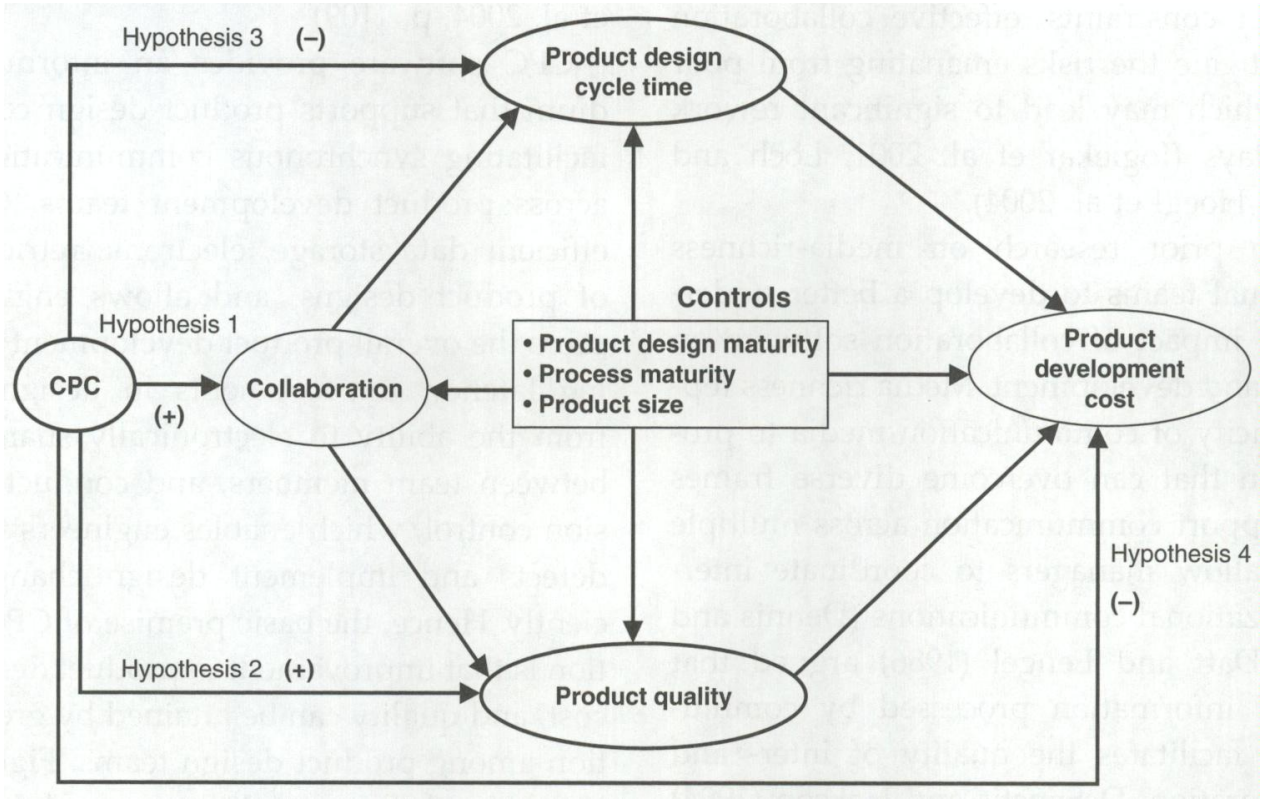

through interactions and shared experience. CPC facilitates socialization by providing a forum for distributed teams to conduct virtual team meetings and communicate through online chat rooms and threaded discussion databases. Team members share tacit design knowledge through shared observation and working with more-experienced mentors. CPC also facilitates externalization, which involves conversion of tacit to explicit knowledge, by providing capabilities for electronic blackboards and design reviews that enable design engineers to share their insights on product designs and conduct design reviews electronically. The externalization mode is initiated by successive iterations of meaningful discussions where team members articulate their perspective and reveal tacit knowledge that is otherwise difficult to share (Nonaka 1994).

Internalization involves conversion of explicit to tacit knowledge where ideas are articulated and improved through an iterative process of trial and error until they are finalized in well-developed form. This mode of collaboration involves team members learning-by-doing where participants share explicit knowledge that is translated (over time) through interactions and experimentation into tacit knowledge. CPC supports internalization, by providing threedimensional visualization, simulation, and graphical analyses capabilities, which enable design teams to share and experiment with different features of product design and gradually develop tacit knowledge based on cumulative experience gained from such trial-and-error processes.

Combination entails reconfiguring existing information by sorting, adding, reclassifying, and integrating different aspects of explicit knowledge into new knowledge (Nonaka 1994). By providing electronic documentation and storage capabilities as well as shared, online databases that facilitate design reuse, CPC software supports knowledge combination by facilitating integration of existing design data into new product designs (Nambisan 2003). Hence, CPC software influences the richness of product design collaboration by facilitating faster information transfer, eliminating redundancies, revising task interdependencies, and allowing for concurrency between different tasks.

Hypothesis 1 (CPC and Collaboration). CPC implementation is associated with an improvement in the level of collaboration, controlling for the impact of process and product design maturity.

\subsection{Product Design Quality}

Product design collaboration typically entails interaction within product design teams, as well as boundary-spanning activities where teams interact across 
departments that involve interfaces with other processes, such as marketing and manufacturing (Hoegl and Gemuenden 2001, Hoegl et al. 2004). New product development projects are typically characterized by concurrent development wherein tasks are carried out in parallel and are dependent on preliminary information from other tasks or modules. This frequently leads to substantial design changes and rework that could consume up to $50 \%$ of engineering capacity and a third of the development budget (Terwiesch et al. 2002). Clark and Fujimoto (1991) suggested that intensive collaboration is a key driver of product development performance, because it allows design teams to release preliminary information early and lets downstream users coordinate future design iterations by providing greater visibility into the change management process.

Design reworks occur if downstream users allocate resources and create designs based on upstream design information that is not stable (Mitchell and Nault 2007). Engineering change orders occur when downstream design decisions are based on upstream design data that is not precise (Terwiesch et al. 2002). The cost of downstream adjustments can be reduced by making downstream decisions so flexible that future adjustments are less costly. By enabling both synchronous (through shared databases or groupware) and asynchronous (through online teamspaces or electronic blackboarding) information exchange, CPC facilitates collaboration between upstream and downstream users by providing greater visibility into the product data and design iteration process. Hence, we hypothesize that by improving the content, timing, and intensity of information exchange, CPC will reduce the need for downstream product design adjustments; this, in turn, leads to better product quality.

Hypothesis 2 (CPC AND Design QuAlity). CPC implementation is associated with greater improvements in product design quality.

\subsection{Product Design Cycle Time}

Product design cycle time is defined as the time elapsed from product conceptualization until final user acceptance of the product design. It is a function of the cycle time required to complete the design (from initial proposal to product design verification and acceptance) as well as the time required to communicate design changes. CPC shortens product design times by allowing design engineers to create final designs more quickly by providing efficient storage and retrieval capabilities and automating computational procedures. By facilitating reuse of past designs, through shared databases and codification of tacit knowledge, CPC allows product design teams to compress the design cycle time (Baba and Nobeoka 1998).

CPC-enabled collaboration also increases product data visibility and provides design engineers with real-time access to the most recent designs, enabling them to evaluate new designs and conduct design iterations rapidly. Design iterations shorten product development times by providing engineers with intuition for the sensitivity of the product design to key design parameters and the robustness of product designs (Eisenhardt and Tabrizi 1995). They also improve designers' cognitive abilities to adapt to new design data; these abilities improve design flexibility and shorten product development times (Eisenhardt 1989). Interteam collaboration also has a positive impact on their ability to adhere to project schedules (Hoegl et al. 2004). Hence, we hypothesize that CPC implementation is associated with a reduction in product design cycle time, after controlling for the impact of design maturity, product size, and process maturity.

Hypothesis 3 (CPC and Design Cycle Time). CPC implementation is associated with a reduction in product design cycle time.

\subsection{Product Development Cost}

By improving the efficiency of work flows associated with product development life cycle management, CPC implementation is associated with a reduction in the number of product design staff as well as documentation and design storage costs. By facilitating real-time collaboration, CPC is also associated directly with a reduction in telecommunication and travel costs required to communicate with users. Furthermore, users are able to avoid software and training costs due to greater standardization of collaboration software across product design teams, hence implementation of CPC has a direct impact on product development costs. 
CPC also reduces latency by reducing the time spent waiting and searching for product information, compresses projects by enabling concurrent work, and facilitates tracking and monitoring of project schedules. It reduces design staff time, which includes time spent in design reengineering, time required to pull inventory and rework, and time spent in product support if product changes or errors are significant. CPC also enables streamlined engineering change order (ECO) implementation by moving from paper-based reporting and tracking to electronic solutions. By reducing rework, eliminating non-valueadded tasks, and identifying functional gaps in product design, CPC reduces overall product development costs. As Terwiesch et al. (2002) observed, early detection and correction of design errors improves downstream manufacturing flexibility and reduces design adjustment costs later if the product information is unstable. Hence, we argue that CPC implementation has a direct impact on product development cost and an indirect impact through its effect on product design quality and design cycle time.

Hypothesis 4 (CPC and Product Development Cost). CPC implementation is associated with a reduction in product development costs.

Organizations that exhibit higher levels of process maturity are more likely to adopt mature project management practices to support product development integration strategies and use quantitative targets to manage projects, mitigate risk, coordinate training, and manage key stakeholders (Krishnan et al. 2000, Harter et al. 2000). The rationale is that, by adopting practices that help to increase process capabilities, product defects can be detected earlier in the design cycle, thus reducing rework to correct design errors detected at later stages (Swanson et al. 1991, Terwiesch et al. 2002). Hence, we control for the impact of process maturity in studying the impact of CPC on product development.

We also control for the impact of product design maturity because prior research suggests that design maturity and product performance have a positive relationship since certain high-performance goals may necessitate more complex product designs, such as more integrated product architectures (Novak and
Eppinger 2001, Ulrich 1995). Prior research in software and product development has shown that product size is a significant predictor of the outcomes of the development (Harter et al. 2000, Eisenhardt and Tabrizi 1995). Hence, we control for the effect of product size to account for the possibility that products designed, with and without CPC, may be significantly different in terms of size and entail different collaboration requirements. Our conceptual research model and hypothesized relationships are shown in Figure 1.

\section{Research Data}

A cross-sectional survey methodology was employed for data collection. An initial survey instrument was tested with respondents from 36 firms to verify whether they were able to understand the survey questions, and to make appropriate adjustments to the variables of interest based on the contextual nature of CPC usage in product development organizations. The initial survey, consisting of an 18-page questionnaire, was used to collect a variety of qualitative and quantitative data regarding the usage of CPC software across the product development life cycle, types of business processes that CPC software support, and the business benefits associated with product development outcomes after CPC implementation.

The final survey questionnaire, as shown in the appendix, was mailed to product development managers and executives at 121 companies that had been identified with the help of a consulting firm as being actively involved in new product design and development. We believe that potential heterogeneity among technologies used for product development is not an issue since we defined the scope and functionality of CPC software in our survey design. We also ensured that respondents understood the types of software that typically fall under the domain of CPC technologies by providing a few examples of vendor software in this category. ${ }^{5}$

A total of 71 firms responded with complete data to the entire questionnaire for an overall response rate

\footnotetext{
${ }^{5}$ This step was necessary to ensure that there was no ambiguity in the definition of CPC and that companies had a clear understanding of the types of software that composed CPC for new product development.
} 
Table 2 Profile of Study Participants by Industry and Firm Characteristics

\begin{tabular}{lcc} 
& Panel A (Study sample) & \\
\hline Industrial category & $\begin{array}{c}\text { Number of } \\
\text { respondents }\end{array}$ & $\begin{array}{c}\text { Percent of } \\
\text { respondents (\%) }\end{array}$ \\
\hline Industrial products & 28 & 39.4 \\
Automotive & 20 & 28.2 \\
Aerospace and defense & 7 & 9.8 \\
High technology/electronics & 9 & 12.7 \\
Other (medical, retail) & 7 & 9.8 \\
Total & 71 &
\end{tabular}

Panel B (Characteristics of publicly traded firms in our sample)

\begin{tabular}{lcccr}
\hline Variable & $N$ & Mean & Std dev & Median \\
\hline Sales (\$, MM) & 57 & 19,482 & 31,960 & 6,099 \\
Margin (\%) & 56 & 28.72 & 17.06 & 29.37 \\
Assets (\$, MM) & 57 & 43,516 & 116,523 & 5,860 \\
R\&D expenditure (\$, MM) & 52 & 804 & 1,007 & 306 \\
\hline
\end{tabular}

Note. MM-millions of dollars.

of $59 \%$. Nonresponse bias was assessed by comparing the annual sales of 56 publicly traded, respondent firms to the annual sales of 45 publicly traded, nonrespondent firms. ${ }^{6} \mathrm{~A} t$-test indicates that there is not statistically significant difference between the two groups $(t=0.61 ; p$ value $=0.29)$. In addition, 10 out of the 50 nonrespondent firms, picked at random, were contacted. We learned that product development managers at these firms were not able to complete the survey because doing so would jeopardize the confidentiality of their operations.

The profile of companies surveyed in this research is shown in Table 2.7 Panel A provides the distribution of survey participants by industry, and Panel B provides a financial snapshot of a subset of publicly traded firms for which data were reported in Compustat, based on their annual sales, margin (i.e., net income and sales), assets, and R\&D spending in the survey year. Fifty-six firms had implemented CPC software as the basic engine for collaboration involving product design, engineering, and end-to-end coordination of the product development process. The

\footnotetext{
${ }^{6}$ The remaining 20 firms were not publicly traded or no sales data were available for the time period of our study.

${ }^{7}$ Although our sample size is relatively small, it is comparable to other studies reported in the product development and software economics literature (Eisenhardt and Tabrizi 1995, Hoegl et al. 2004, Gupta and Wilemon 1990, Harter et al. 2000).
}

remaining 15 firms had not implemented CPC software at the time of the survey. During preliminary screening, we also ensured that project managers had a broad view of the project and could provide data on the survey questions for variables that were measured at different points in time.

For companies that implemented the CPC software, managers were asked to identify two typical products-one designed before the CPC solution was implemented and the other designed after CPC implementation. We collected data for each survey question, before and after implementation of CPC. Respondents were asked to provide their responses on a seven-point Likert scale. For each variable, the difference between before and after CPC implementation responses provides an estimate of the change $(\Delta)$ in outcomes. For CPC nonadopters, we asked managers to identify two typical products, one that was designed a couple of years ago and another that was designed more recently.

A follow-up telephone conversation was conducted with a senior product development executive from each respondent firm to verify the accuracy of the survey responses. These conversations were recorded and provide in-depth details regarding the nature of the CPC implementation and product development processes that were affected by the implementation. We mitigated the effect of potential recall bias by providing a specific context to the CPC implementation and asking respondents to recall events related to CPC usage, software modules that were implemented, and the business processes that were affected after CPC implementation.

We collected additional data on reported cost savings attributed to the dollar savings generated from CPC implementation for a small subset of firms. Savings included cost reductions due to significant reductions in head count, staff design time, inventory exposure due to greater design reuse, design document storage costs, and cost avoidance due to standardization of design software. We observe that the reported cost savings are significantly correlated with the outcomes of CPC implementation collected from our survey data.

\subsection{Construct Measurement}

We defined the product quality construct using items adapted from Adler (1995) and Terwiesch et al. (2002), 
where quality is described as a function of the number of product design defects and ECOs. Design defects represent errors in engineering design when the design is not compatible with technical or functional specifications. Since product designs are often changed after the design specifications are sent to manufacturing, ECOs represent changes that manufacturing sends back to design to ensure producibility (Adler 1995). Hence, ECOs represent a common form of quality problem where the organization coordinates the implementation of design changes proposed by users.

Collaboration is measured as a function of three variables: the frequency of interactions, content of information exchange, and openness to share product design information during collaborative interactions. We drew on early work by Aram and Morgan (1976), who measured team collaboration based on the extent of problem solving though support and integration and the extent of open and authentic communication. We adapted our item definitions to reflect the intensity of collaboration in information-rich media, as described in Hinds and Kiesler (1995), Hoegl and Gemuenden (2001), and Easley et al. (2003). We do not distinguish between within- and across-team collaboration in the context of our study.

Product design cycle time is measured as a function of the length of the design cycle and the average time that it takes to communicate and turn around design changes. The length of the design cycle is measured as the time from product initiation (Phase 0 in Table 1) to the product design verification and manufacturing development phase (Phase 4). Similar measures to define product development cycle times have been reported in the literature on product development (Eisenhardt and Tabrizi 1995, Zirger and Hartley 1996, Griffin 1997).

Product development cost is measured as a function of the cost of product design and prototyping, and the cost of overall product development. We draw on prior work on multiteam $R \& D$ projects where the product development budget is measured as a twoitem scale consisting of product development and prototype costs (Hoegl et al. 2004, Krishnan et al. 2000).

The design maturity construct is measured as the degree of interconnectedness between product components, extent of reuse of existing design features, and the number of new design features. These variables represent the complexity and diversity of a product. Our items were adapted from Novak and Eppinger's (2001) and Griffin's (1997) work on product development.

We defined the process maturity construct based on the capability maturity model-integrated product development (IPD) framework. Process maturity is measured as a function of four items: integration and concurrency of planning and design, quantitative targets for project management, standardized integration practices, and standard practices for work reviews. These indicators reflect best-in-class practices to improve process capabilities that support product development (Harter and Slaughter 2003, Mendelson 2000).

\subsection{Construct Validity and Reliability}

Because our survey data are self-reported, we performed a Harmon's one-factor test to check for common methods bias. First, we computed the difference scores $(\Delta)$ between post-CPC and pre-CPC values for all indicators. ${ }^{8}$ Next, we ran exploratory factor analyses (EFA) on the difference scores that showed the presence of six factor structures consistent with the factors identified in our model. The EFA indicate that explanatory and dependent variables load on different constructs, which suggests that common method bias is not evident in the data (Podsakoff and Organ 1986). Cronbach alpha values for our constructs range in value from 0.68 to 0.87 , which meets the test for internal consistency of our factors.

The $t$-statistics for all factor loadings were significant at the $1 \%$ level and confirm that our measures satisfy convergent validity (Phillips and Bagozzi 1986). To establish discriminant validity, we used a sequential chi-square difference test; it was significant at the $1 \%$ level for all construct pairs (Anderson and Gerbing 1988). We also calculated the average variance extracted (AVE) values for all constructs. They exceed the threshold of 0.5 and are greater than the values of the interconstruct correlations (Fornell and Larcker 1981).

\footnotetext{
${ }^{8}$ That is, $\Delta(X)=X_{\text {post-CPC }}$ minus $X_{\text {pre-CPC}}$, where $X$ represents the value of an indicator. For nonadopters, the difference score $(\Delta)$ was measured as the difference between the corresponding values for recent and older products.
} 


\begin{tabular}{|c|c|c|c|c|c|c|c|}
\hline Construct & $\begin{array}{l}\Delta \text { (Product } \\
\text { quality) }\end{array}$ & $\begin{array}{l}\Delta(\text { Product } \\
\text { dev. cost })\end{array}$ & $\begin{array}{l}\Delta(\text { Product design } \\
\text { cycle time })\end{array}$ & $\Delta$ (Collaboration) & $\Delta($ Design maturity $)$ & $\Delta$ (Process maturity) & $\Delta($ Product size $)$ \\
\hline$\Delta$ (Product quality) & 1.00 & & & & & & \\
\hline$\Delta($ Product dev. cost $)$ & $\begin{array}{l}-0.594 \\
(<0.0001)\end{array}$ & 1.00 & & & & & \\
\hline $\begin{array}{l}\Delta \text { (Product design } \\
\text { cycle time })\end{array}$ & $\begin{array}{l}-0.521 \\
(<0.0001)\end{array}$ & $\begin{array}{c}0.649 \\
(<0.0001)\end{array}$ & 1.00 & & & & \\
\hline$\Delta($ Collaboration $)$ & $\begin{array}{c}0.525 \\
(<0.0001)\end{array}$ & $\begin{array}{l}-0.459 \\
(<0.0001)\end{array}$ & $\begin{array}{l}-0.524 \\
(<0.0001)\end{array}$ & 1.00 & & & \\
\hline$\dot{\Delta}($ Design maturity $)$ & $\begin{array}{c}0.533 \\
(<0.0001)\end{array}$ & $\begin{array}{c}-0.365 \\
(0.002)\end{array}$ & $\begin{array}{l}-0.544 \\
(<0.0001)\end{array}$ & $\begin{array}{c}0.343 \\
(0.003)\end{array}$ & 1.00 & & \\
\hline$\Delta$ (Process maturity) & $\begin{array}{c}0.494 \\
(<0.0001)\end{array}$ & $\begin{array}{l}-0.582 \\
(<0.0001)\end{array}$ & $\begin{array}{l}-0.529 \\
(<0.0001)\end{array}$ & $\begin{array}{c}0.437 \\
(<0.0001)\end{array}$ & $\begin{array}{l}0.399 \\
(0.0006)\end{array}$ & 1.00 & \\
\hline$\Delta($ Product size $)$ & $\begin{array}{c}-0.128 \\
(0.28)\end{array}$ & $\begin{array}{r}-0.041 \\
(0.74)\end{array}$ & $\begin{array}{r}0.044 \\
(0.72)\end{array}$ & $\begin{array}{r}-0.181 \\
(0.13)\end{array}$ & $\begin{array}{l}0.183 \\
(0.13)\end{array}$ & $\begin{array}{r}-0.016 \\
(0.90)\end{array}$ & 1.00 \\
\hline Mean & 0.89 & -1.04 & -1.54 & 1.34 & 0.75 & 1.11 & 0.22 \\
\hline Median & 0.50 & -1.00 & -1.50 & 1.00 & 0.67 & 0.75 & 0 \\
\hline Std. deviation & 1.12 & 1.14 & 1.45 & 1.22 & 1.05 & 1.20 & 1.17 \\
\hline Range & $(-2.0,3.5)$ & $(-4,3)$ & $(-4.5,3)$ & $(-1.0,4.66)$ & $(-2.0,3.33)$ & $(0,5)$ & $(-2,4)$ \\
\hline
\end{tabular}

Note. Two-sided $p$ values are shown in parentheses.

Next, we calculated the mean of the difference scores for all items that belong to a particular factor to compute the value of that factor. Descriptive statistics, as shown in Table 3, indicate that the change in mean and median values and the interfactor correlations are consistent with our hypotheses. A mean value of 0.22 for $\Delta$ (Product size) and a median of 0 suggest that, on the whole, the difference in product size, before and after CPC implementation is quite small. ${ }^{9}$ We performed a confirmatory factor analysis on the difference scores to establish the reliability of our proposed factors. The CFA results are shown in Table 4 . The composite reliability exceeds the recommended value of 0.7 for new scales for all factors, except for $\Delta$ (Collaboration) and $\Delta($ Design maturity) where the reliability is above the threshold of 0.6 (Nunnally and Bernstein 1994).

\section{Analyses and Results}

Our model variables are expressed as difference scores that measure the change in observed values of our model indicators, before and after CPC implementation. For example, $\Delta$ (Collaboration) is expressed as the mean of the difference scores for the three indicators that compose the collaboration factor (i.e., survey

\footnotetext{
${ }^{9}$ Overall, 49 of the 71 firms responded that product size remains
} the same before and after CPC implementation.
Items 7, 8, and 9). Difference scores are useful because they collapse the pre- and post-CPC scores into a single score, and they allow us to control for baseline performance (i.e, pre-CPC). Our use of difference scores is an accepted method, especially in fields such

Table 4 Confirmatory Factor Analyses

\begin{tabular}{|c|c|c|c|c|c|}
\hline Construct & Indicator & $\begin{array}{l}\text { Standardized } \\
\text { loading }\end{array}$ & $t$-statistic & $\begin{array}{l}\text { Composite } \\
\text { reliability }\end{array}$ & AVE \\
\hline$\Delta($ Quality) & $\begin{array}{l}\text { Q1 } \\
\text { Q2 }\end{array}$ & $\begin{array}{l}0.898 \\
0.780\end{array}$ & $\begin{array}{l}8.77 \\
7.30\end{array}$ & 0.83 & 0.84 \\
\hline$\Delta($ Cost $)$ & $\begin{array}{l}\text { Q3 } \\
\text { Q4 }\end{array}$ & $\begin{array}{l}0.747 \\
0.841\end{array}$ & $\begin{array}{l}6.89 \\
7.99\end{array}$ & 0.77 & 0.80 \\
\hline$\Delta($ Cycle time $)$ & $\begin{array}{l}\text { Q5 } \\
\text { Q6 }\end{array}$ & $\begin{array}{l}0.801 \\
0.771\end{array}$ & $\begin{array}{l}7.37 \\
7.05\end{array}$ & 0.76 & 0.79 \\
\hline$\Delta$ (Collaboration) & $\begin{array}{l}Q 7 \\
Q 8 \\
Q 9\end{array}$ & $\begin{array}{l}0.736 \\
0.812 \\
0.428\end{array}$ & $\begin{array}{l}6.27 \\
6.98 \\
2.83\end{array}$ & 0.69 & 0.66 \\
\hline$\Delta($ Design maturity $)$ & $\begin{array}{l}Q 11 \\
\text { Q12 } \\
\text { Q13 }\end{array}$ & $\begin{array}{l}0.694 \\
0.672 \\
0.558\end{array}$ & $\begin{array}{l}5.73 \\
5.52 \\
4.45\end{array}$ & 0.68 & 0.64 \\
\hline$\Delta($ Process maturity $)$ & $\begin{array}{l}\text { Q14 } \\
\text { Q15 } \\
\text { Q16 } \\
\text { Q17 }\end{array}$ & $\begin{array}{l}0.672 \\
0.707 \\
0.920 \\
0.862\end{array}$ & $\begin{array}{l}6.16 \\
6.59 \\
9.74 \\
8.78\end{array}$ & 0.87 & 0.80 \\
\hline
\end{tabular}

Notes. CFA fit statistics: AGFI $=0.88 ; \mathrm{CFI}=0.94$; RMSEA $=0.06$; Chisquare/df $=1.278$. All indicator loadings are statistically significant at $p<0.01$.

CFA - confirmatory factor analysis; CFI-comparative fit index; RMSEAroot mean square error of approximation; AGFI-adjusted goodness of fit statistics. 
as medicine and biostatistics where patient responses to treatments are often measured on an ordinal scale when there does not exist objective metrics for measuring the progression or activity of many types of diseases (Bajorski and Petkau 1999, Shapiro et al. 1998).

We followed a two-step approach to test whether there exists significant differences between the CPC (treatment) and non-CPC (control) groups. First, we ran a Wilcoxon rank sum test on the difference scores. The Wilcoxon statistic, in Mann-Whitney form, was significant for all factors at $p<0.01$, except for $\Delta$ (Design maturity) which was significant at $p<0.10$. Second, we ran an analysis of covariance (ANCOVA) to test whether the mean post-CPC scores in the control and treatment groups were equal. Because regression toward the mean can influence the measurement of the post-CPC score, ANCOVA is considered a valid control technique to remove the influence of the preCPC score on the difference score (Bonate 2000).

\subsection{Estimation Model}

We now describe our estimation model based on the conceptual model in Figure 1.

$$
\begin{aligned}
& \Delta(\text { Collaboration }) \\
& =\phi_{0}+\phi_{1} \text { Collaboration }_{\text {PreCPC }} \\
& +\phi_{2} C P C+\phi_{3} \Delta \text { (Process maturity) } \\
& \left.+\phi_{4} \Delta(\text { Design maturity })+\phi_{5} \Delta \text { (Product size }\right)+\varepsilon_{0}, \\
& \Delta \text { (Product quality) } \\
& =\alpha_{0}+\alpha_{1} \text { Product quality } \text { PreCPC } \\
& +\alpha_{2} C P C+\alpha_{3} \Delta \text { (Process maturity) } \\
& \left.+\alpha_{4} \Delta \text { (Collaboration }\right)+\alpha_{5} \Delta(\text { Design maturity }) \\
& +\alpha_{6} \Delta(\text { Product size })+\varepsilon_{1} \text {, } \\
& =\beta_{0}+\beta_{1} \text { Cycle time }_{\text {PreCPC }}+\beta_{2} C P C \\
& \left.\left.+\beta_{3} \Delta \text { (Process maturity }\right)+\beta_{4} \Delta \text { (Collaboration }\right) \\
& +\beta_{5} \Delta(\text { Design maturity })+\beta_{6} \Delta(\text { Product size })+\varepsilon_{2} \text {, } \\
& =\gamma_{0}+\gamma_{1} \operatorname{Cost}_{\text {PreCPC }}+\gamma_{2} C P C+\gamma_{3} \Delta(\text { Design cycle time })
\end{aligned}
$$

$$
\begin{aligned}
& \left.+\gamma_{4} \Delta \text { (Process maturity }\right)+\gamma_{5} \Delta(\text { Design maturity }) \\
& \left.+\gamma_{6} \Delta \text { (Product quality }\right)+\gamma_{7} \Delta(\text { Product size })+\varepsilon_{3},
\end{aligned}
$$

where $\mathrm{CPC}=1$ if company has implemented and used CPC software for product design, $=0$ otherwise.

We note that our representation of CPC as a dummy variable is similar to the approach proposed by Hitt et al. (2002), where enterprise resource planning (ERP) implementation was modeled as a dummy variable.

We ran a multiple analysis of covariance (MANCOVA) test where the mean difference scores for each factor represent the dependent variable, and the independent variables are represented by the treatment factor and the corresponding pre-CPC score. In other words, we control for the effect of the pre-CPC score on the dependent variable (Shapiro et al. 1998, Hennig et al. 2003)..$^{10}$ For example, in Equation (1) the mean of the difference scores for all indicators of the collaboration factor represents the dependent variable, $\Delta$ (Collaboration), whereas the mean pre-CPC collaboration score represents the independent variable. The MANCOVA test indicates a significant main effect $(p<0.0001$ ) for the effect of CPC on all dependent variables: collaboration, product quality, product design cycle time, and cost.

Our system of equations in (1) through (4) can be estimated efficiently using ordinary least squares (OLS) if the errors across equations are uncorrelated. ${ }^{11}$ However, because each observation in any equation is related to corresponding observations from the same company in the other equations, the error terms in the regressions may be correlated. Therefore, for consistent and efficient estimation, we estimated the system of equations using seemingly unrelated regressions (SURs); this system allows for correlation of disturbances across equations (Lahiri and Schmidt 1978, Greene 1997). We report the estimated unstandardized regression coefficients in Table 5 (Achen 1982, p. 76).

\footnotetext{
${ }^{10}$ We note that the estimation of the treatment effect does not depend on whether we use the post-CPC scores or difference scores as the dependent variables. Both methods produce the same result (Laird 1983).

${ }^{11}$ Our use of ordinal data in OLS regressions is a valid technique (Labovitz 1970, Conover and Iman 1981).
} 
Table 5 SUR Estimation Results

\begin{tabular}{|c|c|c|c|c|}
\hline \multirow[b]{2}{*}{ Independent variable } & \multicolumn{4}{|c|}{ Dependent variable } \\
\hline & $\begin{array}{c}\Delta(\text { Collaboration }) \\
\text { (1) }\end{array}$ & $\begin{array}{c}\Delta \text { (Product quality) } \\
\text { (2) }\end{array}$ & $\begin{array}{c}\Delta \text { (Product design } \\
\text { cycle time }) \\
\text { (3) }\end{array}$ & $\begin{array}{c}\Delta(\text { Product } \\
\text { development cost }) \\
\text { (4) }\end{array}$ \\
\hline Intercept & $\begin{array}{c}2.13^{* * *} \\
(<0.0001)\end{array}$ & $\begin{array}{c}2.30^{* * *} \\
(<0.0001)\end{array}$ & $\begin{array}{c}3.76^{* * *} \\
(<0.0001)\end{array}$ & $\begin{array}{c}2.72^{* * *} \\
(<0.0001)\end{array}$ \\
\hline Pre-CPC score & $\begin{array}{l}-0.59 * * * \\
(<0.0001)\end{array}$ & $\begin{array}{l}-0.55^{* * *} \\
(<0.0001)\end{array}$ & $\begin{array}{l}-0.85^{* * *} \\
(<0.0001)\end{array}$ & $\begin{array}{l}-0.56^{* * *} \\
(<0.0001)\end{array}$ \\
\hline$C P C$ & $\begin{array}{c}1.02^{* * *} \\
(0.001)\end{array}$ & $\begin{array}{l}0.11 \\
(0.664)\end{array}$ & $\begin{array}{r}-0.61^{* *} \\
(0.015)\end{array}$ & $\begin{array}{r}-0.57^{* *} \\
(0.019)\end{array}$ \\
\hline$\Delta($ Process maturity $)$ & $\begin{array}{l}0.17 \\
(0.111)\end{array}$ & $\begin{array}{l}0.02 \\
(0.801)\end{array}$ & $\begin{array}{r}-0.18^{* *} \\
(0.029)\end{array}$ & $\begin{array}{c}-0.23^{* * *} \\
(0.004)\end{array}$ \\
\hline$\Delta$ (Collaboration) & - & $\begin{array}{c}0.32^{* * *} \\
(0.0002)\end{array}$ & $\begin{array}{l}-0.11 \\
(0.174)\end{array}$ & - \\
\hline$\Delta($ Design maturity $)$ & $\begin{array}{l}0.28^{* *} \\
(0.019)\end{array}$ & $\begin{array}{l}0.23^{* *} \\
(0.015)\end{array}$ & $\begin{array}{c}-0.27^{* * *} \\
(0.005)\end{array}$ & $\begin{array}{l}0.12 \\
(0.240)\end{array}$ \\
\hline$\Delta($ Product quality $)$ & - & - & - & $\begin{array}{l}-0.34^{* * *} \\
(0.0004)\end{array}$ \\
\hline$\Delta($ Product size $)$ & $\begin{array}{r}-0.18^{* *} \\
(0.027)\end{array}$ & $\begin{array}{l}-0.07 \\
(0.334)\end{array}$ & $\begin{array}{l}0.04 \\
(0.611)\end{array}$ & $\begin{array}{r}-0.15^{* *} \\
(0.029)\end{array}$ \\
\hline$\Delta($ Product design cycle time $)$ & - & - & - & $\begin{array}{l}0.06 \\
(0.405)\end{array}$ \\
\hline System weighted $R^{2}$ & & & & \\
\hline
\end{tabular}

Notes. The pre-CPC score represents the estimated coefficient of the corresponding dependent variable prior to CPC implementation. For instance, the coefficient of -0.59 in Column (1) corresponds to the coefficient $\phi_{1}$ in Equation (1) of our SUR estimation model.

${ }^{* * *}$ Significance at $p<0.01,{ }^{* *}$ at $p<0.05,{ }^{*}$ at $p<0.10$, respectively ( $p$ values are shown in parentheses for two-tailed tests). The reported values represent unstandardized regression coefficients.

\subsection{Collaboration}

The estimated coefficients, reported in Column (1) of Table 5, indicate that implementation of CPC software has a positive impact on collaboration $\left(\phi_{2}=1.02, p=\right.$ $0.001) .{ }^{12}$ The impact of CPC on $\Delta$ (Collaboration) is statistically significant, and its impact is greater than that of other variables that are associated with the level of collaboration. This result supports Hypothesis 1, and suggests that CPC implementation is associated with significant improvements in the degree of team collaboration during product development.

Our results also indicate that product design maturity has a positive impact on the extent of collaboration $\left(\phi_{4}=0.28, p=0.019\right)$. Products that have a high degree of component interconnectedness and new design features are more likely to require greater collaboration, because they entail strong task interde-

\footnotetext{
${ }^{12}$ The standardized regression coefficient is equal to 0.33 and is also significant at $p<0.01$.
}

pendencies and uncertainty of product design data. ${ }^{13}$ In other words, the need for greater design collaboration is driven by task interdependencies inherent in product design data. Our results further indicate that process maturity has a positive impact on the level of collaboration $\left(\phi_{3}=0.17\right)$, although it is not significant at $p<0.10$.

\subsection{Product Quality}

The results, shown in Column (2) of Table 5, indicate that the direct impact of CPC on product quality is not statistically significant $\left(\alpha_{2}=0.11, p=0.664\right)$. We note that improvements in the level of collaboration after CPC implementation have a positive impact on product quality $\left(\alpha_{4}=0.32, p<0.01\right)$.

\footnotetext{
${ }^{13}$ That is, task interdependencies are greater when product components are highly integrated (as opposed to being modular) and product design data changes rapidly over time as is the case with new product designs.
} 
Because the impact of CPC on product development consists of both direct and indirect (i.e., mediated) effects, we estimate the magnitude and significance of such indirect effects, as well. For instance, the indirect impact of CPC on product quality through its impact on $\Delta($ Collaboration $)$ in Equation (2) is estimated as

$$
\begin{aligned}
\frac{\partial(\Delta \text { Product quality })}{\partial(C P C)}= & \frac{\partial(\Delta \text { Product quality })}{\partial(\Delta \text { Collaboration })} \\
& \cdot \frac{\partial(\Delta \text { Collaboration })}{\partial(C P C)}=\alpha_{4} \cdot \phi_{2} .
\end{aligned}
$$

In other words, the marginal impact of CPC on $\Delta$ (Collaboration) is calculated as " $\partial(\Delta$ Collaboration $) /$ $\partial(C P C)$ " and is represented by $\phi_{2}$, while the marginal impact of $\Delta$ (Collaboration) on $\Delta$ (Product quality) is represented by $\alpha_{4}$. The product of these two terms represents the indirect or mediated impact of CPC on $\Delta$ (Product quality). The overall impact of CPC is then estimated as the sum of the direct and indirect effects, as shown in Table 6 (Row B). The overall impact of $\mathrm{CPC}$ on $\Delta$ (Product quality) is statistically significant (coefficient $=0.530, p=0.063$ ), and our results provide support for Hypothesis 2. Our results imply that CPC-enabled collaboration supports early detection of potential product design flaws which, in turn, prevents quality errors farther downstream that are typically costlier to correct (Harter et al. 2000, Terwiesch et al. 2002). Our results are supported by the analytical model developed by Thatcher and Pingry (2004) and by the anecdotal evidence we collected during interviews:

CPC has reduced the number of reworks required. It's allowed us to catch and correct errors before they are introduced. We're reducing reworks, by not creating the bugs in the first place. There are three aspects of this that result in staff time reductions: the time spent reengineering the design, the time to pull the inventory and rework that, and the time in the field in product support if the change or error was significant. (Manager, hardware engineering services, hightech electronics manufacturer)

Our results also indicate that product design maturity has a significant, positive impact on product quality $\left(\alpha_{5}=0.23, p=0.015\right)$. The result implies that more mature designs are likely to be associated with greater improvements in product quality.

\subsection{Product Design Cycle Time}

The results, shown in Column (3) of Table 5, indicate that the direct impact of CPC on product design cycle time is negative and statistically significant $\left(\beta_{2}=\right.$ $-0.61, p=0.015)$. Our results also indicate that the change in the level of collaboration, after implementation of CPC, is associated with a reduction in product design cycle time $\left(\beta_{4}=-0.11, p=0.174\right)$. We estimated the indirect impact of CPC on product design cycle time as $\beta_{4} * \phi_{2}$, as shown in Row $C$ of Table 6 . While the indirect impact of collaboration is negative but not statistically significant (coefficient $=$ $-0.151, p=0.168$ ), our results imply that CPC is associated with a significant overall reduction in product design cycle time (coefficient $=-0.757, p=0.003$ ).

Our results support Hypothesis 3 and imply that, by enabling product design teams to improve the extent of product design collaboration, CPC allows engineers to communicate design changes faster and

Table 6 Impact of CPC on Product Development Outcomes

\begin{tabular}{lccccc}
\hline & $\begin{array}{c}\text { Direct impact } \\
\text { coefficient } \\
\text { Dependent variable }\end{array}$ & $\begin{array}{c}\text { Collaboration } \\
\text { (II) }\end{array}$ & $\begin{array}{c}\text { Product quality } \\
\text { (III) }\end{array}$ & $\begin{array}{c}\text { Product design } \\
\text { cycle time (IV) }\end{array}$ & $\begin{array}{c}\text { Overall impact } \\
\text { (VI) }\end{array}$ \\
\hline A $\Delta$ (Collaboration) & $1.019^{* * *}$ & - & - & - & $1.019^{* * *}$ \\
& $(0.001)$ & & - & - & $(0.001)$ \\
B $\Delta$ (Product quality) & 0.106 & $0.424^{* * *}$ & - & - & $0.530^{*}$ \\
& $(0.665)$ & $(0.0001)$ & - & $-0.063)$ \\
C $\Delta$ (Product design cycle time $)$ & $-0.606^{* *}$ & -0.151 & - & $-0.757^{* * *}$ \\
& $(0.016)$ & $(0.168)$ & & -0.048 & $-0.795^{* * *}$ \\
D $\Delta$ (Product development cost) & $-0.569^{* *}$ & - & $-0.178^{* * *}$ & $(0.399)$ & $(0.0002)$ \\
\hline
\end{tabular}

${ }^{*} p<0.10,{ }^{* *} p<0.05,{ }^{* * *} p<0.01$. All reported $p$ values are for two-tailed $F$-tests and are shown in parentheses. 
is associated with a significant reduction in the product design cycle time. Our observations are supported by anecdotal evidence:

The CPC software has reduced cycle time to find the product data dramatically. It has also forced us to improve the quality of our data. ... CPC has reduced product design management time for some tasks by a factor of 60 . For example, processing an engineering change order used to take 60 days, now we can do it in a day. On the low end of reduction of cycle time, it has reduced it by about 10 to one. (Director of product life cycle management, Fortune 500 industrial products conglomerate)

We find that process maturity has a significant impact on reduction in product design cycle time, as indicated by its negative coefficient in Column (3) of Table $5\left(\beta_{3}=-0.18, p=0.029\right)$. Our results also suggest that greater product design maturity is associated with a significant reduction in product design cycle time $\left(\beta_{5}=-0.27, p=0.005\right)$. In other words, products that are characterized by greater design reuse and integrated product architectures are, ceteris paribus, more likely to realize significant reductions in product design cycle time.

\subsection{Product Development Cost}

Analyses of the regression results, in Column (4) of Table 5, indicate that CPC has a direct significant impact on reduction in product development $\operatorname{costs}\left(\gamma_{2}=\right.$ $-0.57, p<0.01)$. We observe that CPC also has an indirect effect on product development costs through its impact on $\Delta$ (Product quality) and $\Delta$ (Design cycle time). We note, for instance, that improvements in product design quality are associated with a significant reduction in product development costs $\left(\gamma_{6}=\right.$ $-0.34, p<0.01$ ).

The indirect impact of CPC on $\Delta$ (Product development cost) is estimated as the sum of its marginal impact on product quality and design cycle time. Hence, we have

$$
\begin{aligned}
\frac{\partial(\Delta \text { Product dev. cost })}{\partial(C P C)} \\
=\frac{\partial(\Delta \text { Product dev } \cdot \text { cost })}{\partial(\Delta \text { Product quality })} \cdot \frac{\partial(\Delta \text { Product quality })}{\partial(C P C)} \\
\quad+\frac{\partial(\Delta \text { Product dev. cost })}{\partial(\Delta \text { Design cycle time })} \cdot \frac{\partial(\Delta \text { Design cycle time })}{\partial(C P C)} \\
=\gamma_{6} \cdot\left[\alpha_{2}+\alpha_{4} \cdot \Phi_{2}\right]+\gamma_{3} \cdot\left[\beta_{2}+\beta_{4} \cdot \Phi_{2}\right] .
\end{aligned}
$$

We observe that the indirect impact of CPC on $\Delta$ (Product development cost), as mediated through $\Delta$ (Product quality), is significant at the $1 \%$ level as reported in Row D of Table 6 (coefficient $=-0.178$, $p<0.01$ ). The overall impact of CPC on product development cost is also significant and is primarily caused by the improvement in product quality enabled by CPC. Hence, our results support Hypothesis 4 and provide empirical evidence that is consistent with the analytical model developed by Thatcher and Pingry (2004), who argued that investments in IT lower the fixed cost of product development.

Our regression results also indicate that improvements in process maturity are associated with lower product development costs $\left(\gamma_{4}=-0.23, p=0.004\right)$. Taking our earlier results into account, this indicates that investments in creating mature design processes are associated with lower product development costs. These results are consistent with prior research in software development, as reported by Harter et al. (2000). ${ }^{14}$ We also find that product size has a significant impact on reduction in product development cost $\left(\gamma_{7}=-0.15, p=0.029\right)$. This implies that, ceteris paribus, products that entail a higher number of components are likely to realize greater reductions in product development cost.

In our study, some factors represent reflective constructs based on the definition offered by Jarvis et al. (2003). It is possible that other factors such as product development cost and design cycle time may be construed as formative constructs based on their indicator variables. We explored partial least squares (PLS) estimation because PLS allow us to model both formative and reflective constructs and provide consistent estimates for small sample data (Gefen et al. 2000). We present the results of PLS estimation, using

\footnotetext{
${ }^{14}$ We also accounted for the impact of other factors, such as firm size, industry type, and the time lag since CPC implementation, on the outcomes of product development. None of these additional controls had a significant impact on the reported regression results at $p<0.05$. Furthermore, only one substantial change occurred relative to the results reported in Table 5, where the effect of $\Delta$ (Process maturity) on $\Delta$ (Design cycle time) was not statistically significant when time lag was used as a control variable. Details can be found in an online companion to this paper that is available on the Information Systems Research website (http://isr.pubs.informs.org/ ecompanion.html).
} 


\section{Figure 2 PLS Estimation Results}

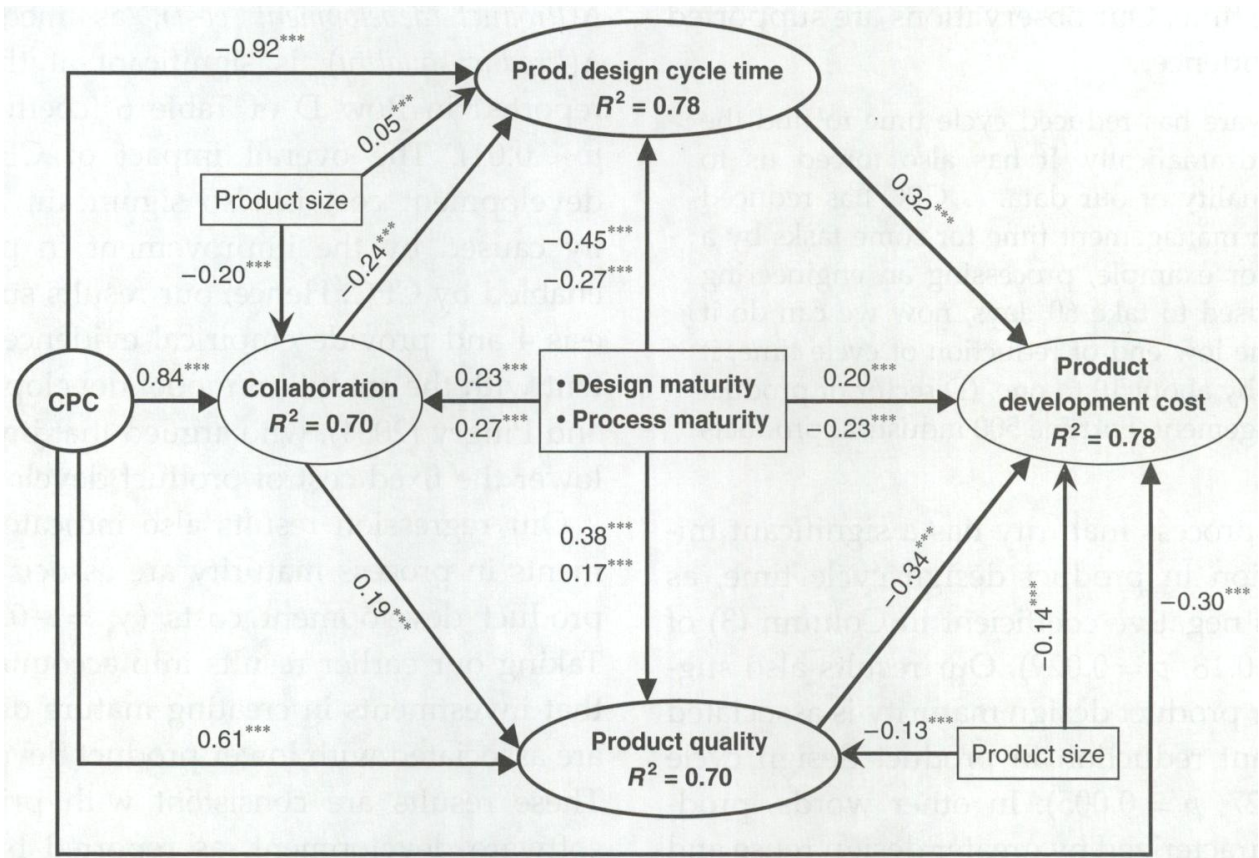

Note. The estimated regression coefficients for design maturity are shown on top followed by the regression coefficients for process maturity shown below.

the PLS procedures described in SAS release 6.11, in Figure 2. Our PLS results are consistent with the SUR estimates, in terms of the significance and direction of the estimated regression coefficients.

We also checked for the possibility that unobserved variation in collaboration may be correlated with product quality and design cycle time. We used an instrumental variables approach described by Hausman (1983). Our results indicate that correlations between unobserved factors that influence collaboration and those that have an impact on product quality or cycle time are not significant.

\subsection{Impact of CPC: An Illustrative Example}

We interviewed product design and development managers for a small subset of our respondent firms to collect more information on the extent of change in product development outcomes after CPC implementation. Managers were probed in an unstructured interview to provide context-specific information regarding the nature of $\mathrm{CPC}$ implementation, usage of CPC across different phases of product development, improvements in process-level metrics, and cost savings associated with product design and development. Based on analyses of archival data and their observations related to CPC implementation, respondents provided their insights on the types of process changes realized after CPC implementation and the substantive changes associated with information work flows related to product development processes.

In Table 7, we have provided an illustrative example of the reported changes in operational metrics associated with product design and development, based on archival data for four firms in different industries. Three types of metrics related to design quality are reported - number of product errors, number of reworks, and number of ECOs-along with the average cost per product error based on their values before and after CPC implementation, for a specific product. Managers responded that CPC-enabled collaboration was associated with improvements in work flows related to more efficient development cycle management. In their firms, CPC had enabled design engineers to streamline ECO implementation by moving from paper-based reporting and tracking to electronic processes, and it reduced their document and design storage costs substantially. By reducing latency and improving visibility of product design data, CPC was associated with a reduction in design staff time 
Table 7 An Illustrative Example of the Impact of CPC on the Operational Outcomes of Product Development

\begin{tabular}{|c|c|c|c|c|c|c|c|c|}
\hline \multirow[b]{2}{*}{ Firm type } & \multicolumn{2}{|c|}{$\begin{array}{l}\text { Number of } \\
\text { product errors }\end{array}$} & \multicolumn{2}{|c|}{$\begin{array}{l}\text { Average cost per } \\
\text { product error }(\$)\end{array}$} & \multicolumn{2}{|c|}{ Number of reworks } & \multicolumn{2}{|c|}{ Number of ECOs } \\
\hline & Before CPC & After CPC & Before CPC & After CPC & Before CPC & After CPC & Before CPC & After CPC \\
\hline $\begin{array}{l}\text { Telecom equipment } \\
\text { manufacturer }\end{array}$ & 250 & 120 & 600 & 300 & 320 & 150 & 1,000 & 600 \\
\hline Industrial machinery & $3 \%$ & $2 \%$ & 10,000 & 5,000 & 1,500 & 1,300 & 1,500 & 1,200 \\
\hline Automotive OEM supplier & 10 & 3 & 50,000 & 45,000 & 3 & 0 & 20 & 10 \\
\hline $\begin{array}{l}\text { High-tech electronic } \\
\text { manufacturing services }\end{array}$ & 50 & 50 & 500 & 400 & 50 & 30 & 250 & 250 \\
\hline
\end{tabular}

that includes time spent in design reengineering, time to pull inventory and rework, and time spent in fieldwork for product support. Greater design maturity associated with reuse of product designs was also associated with a reduction in product inventory exposure.

Table 7 suggests that CPC implementation is associated with substantial changes in product quality, before and after CPC implementation, as suggested by a reduction in the number of product design errors, reworks, and ECOs. For example, a Fortune 500 manufacturer of industrial equipment reported that CPC usage was associated with a $20 \%$ to $25 \%$ improvement in utilization of design engineering time because CPC enabled engineers to easily access accurate product design data in the reconfiguration cycle, a process that would typically take months before the CPC implementation. Similarly, a leading high-technology contract manufacturer of electronics components reported that CPC facilitated greater standardization of product design quality across its manufacturing plants. Thereby, the company was able to reduce surplus inventory significantly due to fewer product reworks (from 50 to 30 , for a typical product) and a reduction in the cost of product errors. These illustrative examples provide further validation of our prior findings based on empirical analyses of survey data.

\section{Discussion}

The development of new types of information technologies is revolutionizing new product development. To the best of our knowledge, our study represents the first attempt to (a) examine the impact of collaboration software in a new product development environment, and (b) propose a causal model of the relationship between IT and product development outcomes that show that improvements in product quality, design cycle time, and cost can be attained through greater collaboration enabled by CPC. We studied the impact of CPC on the product development life cycle using survey data collected from CPC implementations across several industries. We found that implementation of CPC is associated with a significant increase in the extent of product design collaboration. CPC-enabled collaboration is associated with a significant reduction in product design cycle times and development costs. Although CPC does not have a direct impact on product quality, its indirect impact through greater collaboration is significant, which implies that managers should not ignore these mediated effects in their evaluation of the productivity impact of CPC. Similarly, the impact of CPC on reduction in product development cost can be evaluated as a combination of its direct impact and its indirect impact that is mediated through improvements in product design quality and reduction in design cycle time.

Our results also indicate that higher levels of process maturity are associated with a reduction in product design cycle time and development cost. Product design maturity is associated with an increase in product design collaboration and design quality, and a reduction in product design cycle time. These results are consistent with prior research in software and product development. From a theory development perspective, our results suggest that media richness is an important factor in enabling team collaboration during product development. Information-rich media facilitate cross-functional collaboration by providing both synchronous and asynchronous collaboration capabilities that support product development 
processes. These capabilities enable design teams to reduce or eliminate latency and improve their design iteration processes so that design quality problems are detected earlier in the design life cycle. These improvements are associated with significant reductions in product design cycle times and development costs.

\subsection{Limitations}

Our study has several limitations. First, we note that we measured CPC implementation as a binary variable. While such a classification may be useful for an initial study where the objective was to develop and test a model that describes the interrelationships between CPC-enabled collaboration and product development outcomes, future research may entail measuring the extent of CPC usage in greater detail across different types of product design and development activities. A more granular description of the extent of CPC usage, collected through archival records, would provide a more accurate representation of the impact of CPC on product development. A second limitation is that our firm sample was identified with the help of a single consulting firm. Third, the findings of our study are limited due to the relatively small sample size of the data. Additional data collection with a broader cross-section of companies will improve the generalizability of our findings. Fourth, it may be useful to further explore the characteristics of our nonrespondent firms and study the role of CPC in different types of product design environments. Another limitation of our study is that we do not distinguish between interand intrateam design collaboration in the context of our survey design. This provides another avenue to extend the findings of the current research.

\subsection{Future Research}

Our study opens the door for future research to explore several new possibilities. Future research will entail field studies with the objective of closely observing product development projects over time, where we can study the influence of project-specific factors on project outcomes, and observe how the intensity of collaboration changes over time. Future research will include field studies to measure the extent of CPC system usage through system logs and other archival records. Future research may include identifying the critical success factors for CPC implementation and the role of organizational characteristics, such as team size, in moderating the impact of CPC on product development.

Future research must also develop a better understanding of the role of collaboration software across different phases of product development, and study whether CPC-enabled collaboration in earlier phases of product design results in better product performance in later phases. Structural characteristics associated with different types of product design activities may have an impact on the level of collaboration among product design teams. For instance, the extent of CPC usage will vary based on the level of task interdependencies and volatility associated with product design data across different phases of the product development life cycle (Bardhan 2007). Future research can measure the influence of such structuration variables through field-based case studies. Finally, a further avenue for future research is the development of richer analytical models of collaborative interactions that capture the role of IT.

\subsection{Managerial Implications}

Our study has several implications for practice. First, we observe that the extent and nature of product design collaboration plays an important role in determining the impact of collaboration software on the outcomes of product development. As companies implement collaboration tools, it is important to manage the extent to which technology improves the richness and breadth of information exchange. Our findings indicate that it is not sufficient to just measure the direct impact of CPC on product development performance. Rather, it is important to examine whether CPC implementation is accompanied by a corresponding improvement in the quality, frequency, and openness of information exchange among product design teams. Our empirical findings are consistent with Thomke (2006) who observed that the use of IT tools to minimize interfaces during iterative problem solving can significantly improve the fluidity of information exchange and drastically reduce development-cycle times in the global automotive industry.

Second, our results indicate that the benefits of improved collaboration also translate into tangible 
cost savings. Cost savings include reduced inventory exposure due to greater design reuse; and significant reductions in design staff time and the time spent in fieldwork for product support if product changes or errors are significant. Our study of a smaller subset of firms suggests that these cost savings could be significant, and range from a few hundred thousand dollars for small companies to several million dollars for large companies.

Third, our study suggests that a collaboration-based approach to product development provides greater flexibility for decision making because design teams have greater visibility to design data across the entire product development life cycle. In a traditional phasegate approach to product development, the design team needs detailed product specifications that are typically available only late in the design cycle; this increases latency. However, a collaboration-based approach consists of several simultaneous work flows where teams coordinate frequently to decide which information gaps must be filled during prototype testing and when that information would be most useful. Thus, CPC-enabled collaboration provides a platform that allows product development teams to manage information flows rather than process steps (in a phase-gate approach), which eliminates the sources of wait time and reduces the overall product design cycle time significantly (Holman et al. 2003).

\section{Conclusions}

In this study, we developed and empirically validated a model that describes the impact of a specific type of collaboration technology, CPC, on product design and development. Drawing on prior research on theories of media richness and product development and using survey data collected from 71 firms, we found that CPC implementation is associated with a significant reduction in product design cycle time and development cost. CPC is also associated with improvements in product design quality that is mediated through its impact on the extent of design collaboration. Hence, the overall impact of CPC consists of a direct component as well as an indirect component that is mediated through collaboration. The key contribution of this research is to (a) highlight the role of collaboration software in enabling product development processes, and (b) empirically validate the role of collaboration in partially mediating the impact of technology on product development.

We contribute to the emerging literature on the role of IT in product development by proposing and empirically testing a framework to study the impact of IT in product development organizations, an area that has been identified as fertile for interdisciplinary IS research applications (Nambisan 2003). Our research also includes an initial attempt to validate the survey responses through an objective data collection effort and to link the operational impact of CPC to improvements in process-level metrics observed during product development.

\section{Acknowledgments}

Comments on an earlier version from Vish Krishnan, Robert Kauffman, Robert Zmud, Satish Nambisan, K. K. Sinha, the senior editor, the associate editor, two anonymous referees, and seminar participants at the University of Minnesota Workshop on Information Systems and Economics (WISE), and 2004 INFORMS Conference on Information Systems and Technology (CIST) are gratefully acknowledged.

\section{Appendix. Survey Questionnaire}

Collaborative product commerce (CPC) is a class of collaboration software and tools that uses Internet technologies to permit individuals to collaboratively share intellectual data for the design, development, and management of product data throughout the product design and development life cycle. CPC includes work-flow tools that enable real-time exchange of product design data using structured business processes.

Firm Name: __ Number of employees:

Has your organization implemented a CPC solution for product design and development?

a. If yes, when was it implemented? _ Month _ Year.

Please identify two typical products that your company designed and brought to market. Of these two products, please identify (i) one product that was designed before the CPC solution was implemented and (ii) one product that was designed using the CPC solution.

b. If No, please identify two typical products: one that was designed a couple of years ago and another that was designed more recently. Please provide your responses to the questions below based on these two products. 
Please comment on the following product-related statements as they relate to your product development organization. Provide a rating for each question based on the following scale.

Very low - Moderate - Very high (1-7-point Likert scale)

\section{Product Quality}

Q1. Evaluate product quality based on the number of product design errors or defects

a. before the CPC solution was deployed.

b. after the CPC solution was deployed.

Q2. Evaluate product quality based on the number of ECOs

a. before the CPC solution was deployed.

b. after the CPC solution was deployed.

\section{Product Development Cost}

Q3. Evaluate the cost of product design and prototyping

a. before the CPC solution was deployed.

b. after the CPC solution was deployed.

Q4. Evaluate the cost of overall product development

a. before the CPC solution was deployed.

b. after the CPC solution was deployed.

\section{Product Design Cycle Time}

Q5. Evaluate the length of the product design cycle time

a. before the CPC solution was deployed.

b. after the CPC solution was deployed.

Q6. Evaluate the average time it takes to communicate design changes related to product development

a. before the CPC solution was deployed.

b. after the CPC solution was deployed.

\section{Collaboration}

Q7. Evaluate the frequency of collaborative interactions related to product design and development

a. before the CPC solution was deployed.

b. after the CPC solution was deployed.

Q8. Evaluate the extent (content) of detailed design information exchanged during collaborative interactions related to product development

a. before the CPC solution was deployed.

b. after the CPC solution was deployed.

Q9. Evaluate the openness to share product design information during collaborative interactions related to product development

a. before the CPC solution was deployed.

b. after the CPC solution was deployed.

\section{Product Size}

Q10. Evaluate the number of components used in a typical product designed

a. before the CPC solution was deployed.

b. after the CPC solution was deployed.

\section{Design Maturity}

Q11. Evaluate the typical degree of interconnectedness between product components

a. before the CPC solution was deployed.

b. after the CPC solution was deployed.

Q12. Evaluate the typical number of new product design features

a. before the CPC solution was deployed.

b. after the CPC solution was deployed.

Q13. Evaluate the typical extent of reuse of existing design features in the products designed

a. before the CPC solution was deployed.

b. after the CPC solution was deployed. 
Provide a rating for each question based on the following scale:

Strongly disagree - Neither agree nor disagree - Strongly agree (1-7-point Likert scale)

\section{Process Maturity}

Q14. Integrated processes exist to ensure that product life-cycle processes are identified and planned concurrently with design

a. before the CPC solution was deployed.

b. after the CPC solution was deployed.

Q15. Quantitative targets are used to manage projects, manage suppliers, support risk management, coordinate training, and coordinate among project stakeholders

a. before the CPC solution was deployed.

b. after the CPC solution was deployed.

Q16. The organization has standard practices to support its product integration strategy for developing and integrating components, and delivering the product to the customer

a. before the CPC solution was deployed.

a. after the CPC solution was deployed.

Q17. Work products, processes, and services are objectively evaluated against the applicable requirements to ensure that issues arising from these reviews are addressed

a. before the CPC solution was deployed.

b. after the CPC solution was deployed.

\section{References}

Achen, C. 1982. Interpreting and Using Regression. Sage Publications, New Delhi, India.

$\rightarrow$ Adler, P. S. 1995. Interdepartmental interdependence and coordination: The case of the design-manufacturing interface. Organ. Sci. 6(2) 147-167.

Ancona, D. G., D. F. Caldwell. 1990. Information technology and work groups: The case of new product teams. J. Galegher, R. Kraut, C. Egido, eds. Intellectual Teamwork: Social and Technological Foundations of Cooperative Work. Lawrence Erlbaum Associates, Hillsdale, NJ, 173-190.

Ancona, D. G., D. F. Caldwell. 1992. Bridging the boundary: External activity and performance in organizational teams. Admin. Sci. Quart. 37 634-665.

Anderson, J. C., D. W. Gerbing. 1988. Structural equation modeling in practice: A review and recommended two-step approach. Psych. Bull. 103 411-423.

$\rightarrow$ Aram, J. D., C. P. Morgan. 1976. The role of project team collaboration in R\&D performance. Management Sci. 22(10) 1127-1137.

Baba, Y., K. Nobeoka. 1998. Toward knowledge-based product development: The 3-D CAD model of knowledge creation. Res. Policy 26 643-659.

Bajorski, P., J. Petkau. 1999. Nonparametric two-sample comparisons of changes on ordinal responses. J. Amer. Statist. Assoc. 94(447) Theory and Methods 970-978.

Bardhan, I. R. 2007. Toward a theory to study the use of collaborative product commerce for product development. Inform. Tech. Management 8(2).

Bonate, P. 2000. Analysis of Pretest-Posttest Designs. Chapman \& Hall, CRC Press, Boca Raton, FL.

$\rightarrow$ Brown, S., K. M. Eisenhardt. 1995. Product development: Past research, present findings and future directions. Acad. Management Rev. 20(2) 343-378.

Carroll, M. 2001. Collaborative commerce: The next big thing in global manufacturing. eAI Journal (July) 20-24.
Clark, K. B., T. Fujimoto. 1991. Product Development Performance: Strategy, Organization and Management in the World Auto Industry. Harvard Business School Press, Boston, MA.

$\rightarrow$ Conover, W. J., R. L. Iman. 1981. Rank transformations as a bridge between parametric and nonparametric statistics. Amer. Statistician 35(3) 124-129.

$\rightarrow$ Daft, R. L., R. H. Lengel. 1986. Organizational information requirements, media richness, and structural design. Management Sci. 32(5) 554-571.

Davis, J., E. Subramanian, S. Konda, H. Granger, M. Collins, A. Westerberg. 2001. Creating shared information spaces to support collaborative design work. Inform. Systems Frontiers 3(3) 377-392.

De Meyer, A. 1991. Tech talk: How managers are stimulating global R\&D communication. Sloan Management Rev. (Spring) 49-58.

$\rightarrow$ Dennis, A. R., S. T. Kinney. 1998. Testing media richness theory in the new media: The effects of cues, feedback, and task equivocality. Inform. Systems Res. 9(3) 256-274.

$\rightarrow$ DeSanctis, G., B. M. Jackson. 1994. Coordination of information technology management: Team-based structures and computer-based communication systems. J. Management Inform. Systems 10(4) 85-110.

$\rightarrow$ Easley, R. F., S. Devaraj, M. Crant. 2003. Relating collaborative technology use to teamwork quality and performance: An empirical analysis. J. Management Inform. Systems 19(4) 247-268.

$\rightarrow$ Eisenhardt, K. M. 1989. Building theories from case study research. Acad. Management Rev. 14(4) 532-550.

Eisenhardt, K. M., B. Tabrizi. 1995. Accelerating adaptive processes: Product innovation in the global computer industry. Admin. Sci. Quart. 40 84-110.

$\rightarrow$ Fornell, C., D. Larcker. 1981. Evaluating structural equation models with unobservable variables and measurement errors. J. Marketing Res. 18(1) 39-50.

Gefen, D., D. W. Straub, M.-C. Boudreau. 2000. Structural equation modeling and regression: Guidelines for research practice. Comm. Assoc. Inform. Systems 4(7) 2-77.

Gerwin, D., L. Moffat. 1997. Authorizing processes changing team autonomy during new product development. J. Engrg. Tech. Management 14 291-313. 
Greene, W. 1997. Econometric Analysis, 3rd ed. MacMillan Publishing Company, New York.

Griffin, A. 1997. The effect of project and process characteristics on product development cycle time. J. Marketing Res. 34 24-35.

$\rightarrow$ Gupta, R., D. Wilemon. 1990. Accelerating the development of technology-based new products. California Management Rev. 32(2) 24-44.

Harter, D. E., S. Slaughter. 2003. Quality improvement and infrastructure activity costs in software development: A longitudinal analysis. Management Sci. 49(6) 84-800.

$\rightarrow$ Harter, D. E., M. S. Krishnan, S. Slaughter. 2000. Effects of process maturity on quality, cycle time, and effort in software product development. Management Sci. 46(4) 451-466.

Hausman, J. 1983. Specification and estimation of simultaneous equation models. Z. Griliches, M. Intriligator, eds. Handbook of Econometrics, Vol. 1. North Holland Publishers, New York, 403426.

Hennig, C., D. Mullensiefen, J. Bargmann. 2003. Comparison of changes in a pretest-posttest design with Likert scales. Research Report 113, Eidgenossische Technische Hoschschule, Zurich, Switzerland.

$\rightarrow$ Hinds, P., S. Kiesler. 1995. Communication across boundaries: Work, structure, and use of communication technologies in a large organization. Organ. Sci. 6(4) 373-393.

$\rightarrow$ Hitt, L. M., D. J. Wu, X. Zhou. 2002. Investment in enterprise resource planning: Business impact and productivity measures. J. Management Inform. Systems 19(1) 71-98.

Hoegl, M. M., H. G. Gemuenden. 2001. Teamwork quality and the success of innovative projects: A theoretical concept and empirical evidence. Organ. Sci. 12(4) 435-449.

$\rightarrow$ Hoegl, M. M., K. Weinkauf, H. G. Gemuenden. 2004. Interteam coordination, project commitment, and teamwork in multiteam R\&D projects: A longitudinal study. Organ. Sci. 15(1) 38-55.

Holman, R., H.-W. Kaas, D. Keeling. 2003. The future of product development. McKinsey Quart. (3) 28-39.

$\rightarrow$ Jarvis, C. B., S. B. Mackenzie, P. M. Podsakoff. 2003. A critical review of construct indicators and measurement model misspecification in marketing and consumer research. J. Consumer Res. 30(2) 199-218.

$\rightarrow$ Joglekar, N., A. A. Yassine, S. D. Eppinger, D. E. Whitney. 2001. Performance of coupled product development activities with a deadline. Management Sci. 47(12) 1605-1620.

$\rightarrow$ Krishnan, M. S., C. Kriebel, S. Kekre, T. Mukhopadhyay. 2000. An empirical analysis of productivity and quality in software products. Management Sci. 46(6) 745-759.

$\rightarrow$ Krishnan, V., K. Ulrich. 2001. Product development decisions: A review of the literature. Management Sci. 47(1) 1-21.

$\rightarrow$ Labovitz, S. 1970. The assignment of numbers to rank order categories. Amer. Sociol. Rev. 35(2) 515-524.

Lahiri, K., P. Schmidt. 1978. On the estimation of triangular structural systems. Econometrica 46 1217-1221.

Laird, N. 1983. Further comparative analyses of pretest-posttest research designs. Amer. Statistician 37329.

Liker, J. K., M. Fleischer, D. Arnsdorf. 1992. Fulfilling the promised of CAD. Sloan Management Rev. (Spring) 74-86.

$\rightarrow$ Loch, C., C. Terwiesch. 1998. Communication and uncertainty in concurrent engineering. Management Sci. 44(8) 1032-1048.

Maznevski, M. L., K. L. Chudoba. 2000. Bridging space over time: Global virtual team dynamics and effectiveness. Organ. Sci. 11(5) 473-492.
McGrath, M., M. Iansiti. 1998. Envisioning IT-enabled innovation. Insight Magazine 2-10.

$\rightarrow$ Mendelson, H. 2000. Organizational architecture and success in the information technology industry. Management Sci. 46(4) 513-529.

Mitchell, V. L., B. R. Nault. 2007. Cooperative planning, uncertainty, and managerial control in concurrent design. Management Sci. Forthcoming.

$\rightarrow$ Moenaert, R. K., W. E. Souder. 1996. Context and antecedents of information utility at the $R \& D /$ marketing interface. Management Sci. 42(11) 1592-1610.

Mulani, N., H. Lee. 2001. New business models for supply chain excellence. Achieving Supply Chain Excellence Through Technology, 4. Montgomery Research, San Francisco, CA, 14-18.

Mulani, N., J. Matchette. 2001. Lifecycle collaboration: Linking strategy and execution to sustain superior performance. Achieving Supply Chain Excellence Through Technology, 4. Montgomery Research, San Francisco, CA, 206-208.

Nambisan, S. 2002. Designing virtual customer environments for new product development: Toward a theory. Acad. Management Rev. 27(3) 392-413.

$\rightarrow$ Nambisan, S. 2003. Information systems as a reference discipline for new product development. MIS Quart. 27(1) 1-18.

$\rightarrow$ Nonaka, I. 1994. Dynamic theory of organizational knowledge creation. Organ. Sci. 5(1) 14-37.

Novak, S., S. Eppinger. 2001. Sourcing by design: Product complexity and the supply chain. Management Sci. 47(1) 189-204.

Nunnally, J. C., I. H. Bernstein. 1994. Psychometric Theory. McGraw Hill, New York.

O'Marah, K. 2001. Make to desire: How new technologies are revolutionizing life cycle management. Achieving Supply Chain Excellence Through Technology. Montgomery Research, San Francisco, CA.

Phillips, L., R. Bagozzi. 1986. Assessing measurement error in key informant reports: A methodological note on organizational analysis in marketing. J. Marketing Res. 18 395-415.

Podsakoff, P. M., D. W. Organ. 1986. Self-reports in organizational research: Problems and prospects. J. Management 12(4) 531-544.

Port, O. 2003. Design tools move into the fast lane: New software turns ideas into reality in record time. BusinessWeek (June 2).

Shapiro, S. L., G. E. Schwartz, G. Bonner. 1998. Effects of mindfulness-based stress reduction on medical and pre-medical students. J. Behav. Medicine 21(6) 581-598.

Sosa, M. E., S. Eppinger, M. Pich, D. McKendrick, S. Stout. 2002. Factors that influence technical communication in distributed product development: An empirical study in the telecommunications industry. IEEE Trans. Engrg. Management 49(1) 45-58.

Swanson, K., D. McComb, J. Smith, D. McCubbrey. 1991. The application software factory: Applying total quality techniques to systems development. MIS Quart. 5(4) 566-580.

$\rightarrow$ Terwiesch, T., C. Loch, A. De Meyer. 2002. Exchanging preliminary information in concurrent engineering. Organ. Sci. 13(4) 402-419.

Thatcher, M. E., D. Pingry. 2004. An economic model of product quality and IT value. Inform. Systems Res. 15(3) 268-286.

Thomke, S. 2006. Capturing the real value of innovation tools. Sloan Management Rev. 47(2) 24-32.

Thomke, S., D. Reinertsen. 1998. Agile product development: Managing development flexibility in uncertain environments. California Management Rev. 41(1) 8-30. 
Tushman, M. L. 1977. Special boundary roles in the innovation process. Admin. Sci. Quart. 22 587-605.

Ulrich, K. 1995. The role of product architecture in the manufacturing firm. Res. Policy 24 419-440.

$\rightarrow$ Vickery, S., C. Droge, T. P. Stank, T. J. Goldsby, R. E. Markland. 2004. The performance implications of media richness in a businessto-business service environment: Direct versus indirect effects. Management Sci. 50(8) 1106-1119.
Welty, B., I. Becerra-Fernandez. 2001. Managing trust and commitment in collaborative supply chain relationships. Comm. ACM 44(6) 67-73.

Yassine, A., K. C. Kim, T. Roemer, M. Holweg. 2004. Investigating the role of IT in customized product design. Production Planning and Control 15(4) 422-434.

Zirger, B. J., J. L. Hartley. 1996. The effect of acceleration techniques on product development time. IEEE Trans. Engrg. Management 43(2) 143-152. 